\title{
Design of Polymer Blends Based on Chitosan:POZ with Improved Dielectric Constant for Application in Polymer Electrolytes and Flexible Electronics
}

\author{
Shujahadeen B. Aziz $\mathbb{D}^{1,2}$ M. H. Hamsan, ${ }^{3}$ M. F. Z. Kadir, ${ }^{3}$ and H. J. Woo ${ }^{4}$ \\ ${ }^{1}$ Hameed Majeed Advanced Polymeric Materials Research Lab., Department of Physics, College of Science, \\ University of Sulaimani, Qlyasan Street, Sulaimani, Kurdistan Regional Government, Iraq \\ ${ }^{2}$ Komar Research Center (KRC), Komar University of Science and Technology, Sulaimani 46001, \\ Kurdistan Regional Government, Iraq \\ ${ }^{3}$ Centre for Foundation Studies in Science, University of Malaya, Kuala Lumpur, Malaysia \\ ${ }^{4}$ Centre for Ionics, Faculty of Science, University of Malaya, Kuala Lumpur, Malaysia \\ Correspondence should be addressed to Shujahadeen B. Aziz; shujaadeen78@yahoo.com
}

Received 6 March 2019; Revised 10 October 2019; Accepted 27 December 2019; Published 17 January 2020

Academic Editor: Leandro Gurgel

Copyright ( $\odot 2020$ Shujahadeen B. Aziz et al. This is an open access article distributed under the Creative Commons Attribution License, which permits unrestricted use, distribution, and reproduction in any medium, provided the original work is properly cited.

\begin{abstract}
There is a considerable demand for the development and application of polymer materials in the flexible electronic-and polymerbased electrolyte technologies. Chitosan (CS) and poly(2-ethyl-2-oxazoline) (POZ) materials were blended with different ratios to obtain CS:POZ blend films using a straightforward solution cast technique. The work was involved a range of characteristic techniques, such as impedance spectroscopy, X-ray diffraction (XRD), and optical microscopy. From the XRD spectra, an enhancement in the amorphous nature in CS:POZ blend films was revealed when compared to the pure state of CS. The enhancement was verified from the peak broadening in CS:POZ blend films in relative to the one in crystalline peaks of the CS polymer. The optical micrograph study was used to designate the amorphous and crystalline regions by assigning dark and brilliant phases, respectively. Upon increasing POZ concentration, the dielectric constant was found to increase up to $\varepsilon^{\prime}=6.48$ (at $1 \mathrm{MHz}$ ) at $15 \mathrm{wt} . \%$ of POZ, and then a drop was observed beyond this amount. The relatively high dielectric constant and dielectric loss were found at elevated temperatures. The increase of POZ concentration up to $45 \mathrm{wt} \%$ made the loss tangent to shift to the lower frequency side, which is related to increasing resistivity. The increases of dielectric constant and dielectric loss with temperature were attributed to the increase of polarisation. The loss tangent peaks were found to shift to the higher frequency side as temperature elevated. Obvious relaxation peaks were observed in the imaginary part of electric modulus, and no peaks were found in the dielectric loss spectra. The concentration dependent of $M^{\prime \prime}$ peaks was found to follow the same trend of loss tangent peaks versus POZ content. The relaxation process was studied in terms of electric modulus parameters.
\end{abstract}

\section{Introduction}

Chitosan (CS) is a linear polysaccharide, bioderivative of the second most abundant natural chitin polymer after cellulose [1], which is obtained mainly from shells of crustaceans, jellyfish, or corals. The advantage of CS over the other polysaccharides is based on its biocompatibility and a variety of interesting properties, such as anti-inflammatory, antimicrobial, antitumor, and immunity-enhancement properties. It serves as a multifunctional compound that can be used in biomedical purposes [2]. Another important property of CS is the nontoxicity and natural biodegradability. However, the pure state of CS shows a relatively low ionic conductivity. Natural polymers usually have normal inclination to decay in comparison to the indestructible synthetic polymer [3]. There are two organic functional groups, known as amine $\left(-\mathrm{NH}_{2}\right)$ and hydroxyl $(-\mathrm{OH})$, on the CS backbone structure, which are responsible in complex 
formation with inorganic salts [4]. To minimise the crystalline region inside the polymer matrices resulting in an increase in the ionic conductivity, several methodologies have been adapted in this modification, such as crosslinking, polymer grafting, and polymer blending and incorporating inorganic fillers $[5,6]$. Recently, natural polymer blending has become an attractive methodology and strong alternative in replacing synthetic polymers in many applications. In addition, its favourable features, for example, being a renewable resource, nontoxic, inexpensive, and biodegradable, make it a preferable polymer design. Among natural polymers, chitosan and its blend designs have received extreme interest owing to their versatility and flexibility for a large number of applications as discussed earlier [7]. The existence of biodegradable constituents in blend polymers has been taken into consideration, especially in the case of the applications in the disposable packaging industry or for medicine [8]. This methodology is considered as a convenient route for the design of new polymeric materials with new valuable properties which are superior to those of the individual components. Moreover, the route is usually inexpensive and less time-consuming in the synthesising of polymeric materials with invaluable features than that of the monomers and/or new polymerisation routes [9]. Thakur et al. documented blending of two strongly polar polymers, e.g., poly(arylene ether urea) (PEEU), $\varepsilon^{\prime}=4.7$, and aromatic polythiourea (ArPTU), $\varepsilon^{\prime}=4.4$, resulting in a mixture that exhibits a relatively high dielectric constant, $\varepsilon^{\prime}=7.5$ and maintaining low dielectric loss $(<1 \%)$ [10]. Recent studies revealed that there is a huge demand for synthesising polymer materials for flexible electronics; among them, polymers with a high dielectric constant play a vital role. For example, a polymer blend that is based on poly (2-cyanoethyl vinyl ether) (CEPVA) and poly(methyl methacrylate) (PMMA) with relatively high dielectric constant has been reported [11]. It is well documented that nonbiodegradable hydrophilic and water-soluble polymers such as poly(ethylene oxide) (PEO) or poly(vinyl alcohol) (PVA) have sufficient compatibility with natural or biopolymers [8]. To pinpoint, a number of blended polymers that are based on natural chitosan such as chitosan:poly-D,L-lactide-co-glycoside (CS:PLGA) [2], CS:PVA [12], and CS:PEO [8, 13], chitosan: hydroxypropyl methylcellulose (CS:HPMC) [14], chitosan:cellulose (CS:C) [15] have been reported in the literature. Recently, Abilova et al. [16] have studied the chitosan/poly(2-ethyl-2-oxazoline) films in favor of ocular drug delivery. In their study, they have showed that CS:POZ has good miscibility. Moreover, Shubha et al. [17] have documented the influence of polyvinylpyrrolidone (PVP) on the physical properties of POZ. From the electrolyte and electronic point of view, polymer blend fabrication with high dielectric constant is found to be very important. Obviously, choosing polymers with electrolyte character depends mainly upon the presence of polar groups. This is attributed to the sufficient electron donor capability that allows them in forming coordination with cations and making less steric hindrance to bond rotation [18]. Up to date, a vast number of research studies revealed that POZ has been focused as promising candidates in biomedical applications $[19,20]$. To be clarified, glass transition temperature $\left(T_{\mathrm{g}}\right)$ of $\mathrm{POZ}$ is as low as $63^{\circ} \mathrm{C}$ [19], whereas $T_{\mathrm{g}}$ for CS is relatively quite high and found to be above $200^{\circ} \mathrm{C}[21,22]$. Consequently, blending of CS with POZ can be interesting in developing new polymers with relatively high chain flexibility.

This study intends to explore a novel approach in the fabrication of high dielectric constant polymer blends. The design of polymer blends with high dielectric constant is of major importance from the viewpoint of flexible electronics and polymer electrolytes for battery and supercapacitor technology. The fabricated polymer-based samples are found to exhibit a relatively high dielectric constant of $\varepsilon^{\prime}=6.48$ at high frequencies, using an easy route. The methodology can be considered as an innovative method in designing favored polymers with desired dielectric constant.

\section{Experimental Detail}

2.1. Polymer Blend Preparation. The materials of chitosan (CS), a natural biomolecule with average molecular weight of 310,000 to $375,000 \mathrm{~g} / \mathrm{mol}$, and poly(2-ethyl-2-oxazoline) (POZ) powder, with average molecular weight of $200,000 \mathrm{~g} /$ mol, were purchased from Sigma-Aldrich. They were used as raw materials in the synthesis of blend polymer films, using the solution cast technique. Initially, $0.5 \mathrm{gm}$ of CS was dissolved in $50 \mathrm{~mL}$ of acetic acid (1 wt.\%) solution at room temperature. A series of different concentrations of $\mathrm{POZ}$ was then dissolved in distilled water. Afterwards, both POZ and CS solutions were mixed to synthesize blend polymer samples. These mixtures were continuously stirred until homogeneous solutions were obtained. The samples were labeled as PBS1, PBS2, and PBS3 for SC incorporated with 15,30 , and $45 \mathrm{wt} . \%$ of POZ, respectively. Again, mixtures were stirred using a magnetic stirrer for a longer period of time, up to two hours. The solutions were then cast into clean and dry plastic Petri dishes, and the solvent was allowed to evaporate at room temperature until solvent-free films were obtained. The films were kept in desiccators with blue silica gel desiccant for further drying.

\subsection{Characterization Techniques. X-Ray diffraction (XRD)} patterns were acquired using the Empyrean X-ray diffractometer (PANalytical, the Netherlands) with operating current and voltage of $40 \mathrm{~mA}$ and $40 \mathrm{kV}$, respectively. The samples were irradiated with a beam of monochromatic $\mathrm{CuK} \alpha \mathrm{X}$-radiation of wavelength $\lambda=1.5406 \AA$, and the glancing angle $\mathrm{X}$-ray diffraction was in the range of $5^{\circ} \leq 2 \theta \leq 80^{\circ}$ with a step size of $0.1^{\circ}$. The surface morphology of the solid films was studied using an optical microscope (MEIJI, model). For any individual sample, the surface images were taken at a fixed magnification using a highquality digital camera attached to the optical microscope and connected to a software control (DinoCapture). The impedance of the films was measured using an HIOKI $3531 \mathrm{Z}$ Hi-tester hyphenated to a computer with a frequency range of $50 \mathrm{~Hz}-1000 \mathrm{kHz}$. The electrochemical measurements were performed in a temperature ranging from $303 \mathrm{~K}$ to $353 \mathrm{~K}$. The software could manage the measurements and 
calculation of the real and imaginary parts of the impedance. For this purpose, the SPE films ( $2 \mathrm{~cm}$ diameter) were cut and sandwiched between two stainless steel electrodes with the aid of spring clips to guarantee a sufficient contact.

\section{Results and Discussion}

3.1. XRD Study. It is well known that polymer materials are either amorphous or semicrystalline [23]. To predict crystallinity of a polymer structure, it is of a great importance to have an accurate method. This is not only useful in determining the molecular structure of a crystalline polymer but also in understanding and rationalizing the intrinsic properties of polymeric materials that have a major influence on crystal packing [24]. Figure 1 presents the XRD pattern of neat CS. Indeed, the CS membrane in the pure state has two peaks as a result of crystalline domain of the CS polymer where one of them is at $14.5^{\circ}$ and the other at $20.9^{\circ}$. To pinpoint it, the two peaks are related to two different types of crystals [25]; the first peak is centered at $14.5^{\circ}$ and is correlated to the crystal having a unit cell of $a=7.76, b=10.91$, $c=10.30\left({ }^{\circ} \mathrm{A}\right), \beta=90^{\circ}$, and the unit cell of a crystal corresponding to $14.5^{\circ}$ consists of two monomer units along the main chain axis. The other one peaked at $20.9^{\circ}$ which is associated to the crystal in the chitosan membrane. The unit cell of the crystal corresponding to $2 \theta=20.9^{\circ}$ has the following lattice parameters: $a=4.4, b=10.0, c=10.30\left({ }^{\circ} \mathrm{A}\right)$, and $\beta=90^{\circ}[26]$. The broad X-ray peak feature can be seen at around $2 \theta=41^{\circ}$ in Figure 1. As far as we know from the literature, these broad peaks in the XRD pattern of pure polymers result from interchain segment scattering in the amorphous state [10]. It is evidenced that, with an increase in POZ (15 wt.\% and 45 wt.\%), the crystallinity of CS scarified moderately as depicted in Figure 2. It is well documented that POZ is defined as an amorphous polymer, determining from the two broad amorphous humps centered at $2 \theta=10.4^{\circ}$ and $18.8^{\circ}[16,17,27]$. The blending of POZ with the CS polymer induces the crystallinity to be reduced, and this can be explained based on the formation of hydrogen bonding between POZ and CS matrices. It is well defined that the hydrogen bonding is occurred from the interaction of electron-deficient hydrogen with a high electron density region. In fact, hydrogen bonding (H-bonding) as an intermolecular interaction can be described as $X-H, \ldots, Y$, where $X$ and $Y$ are electronegative elements, and $Y$ has only one or more lone electron pairs. In other words, $X$ and $Y$ elements can be F, O, and $\mathrm{N}$ atoms [9]. From the molecular structure of POZ (see Scheme 1(a)), one can clearly see that the monomer of POZ contains $\mathrm{O}$ and $\mathrm{N}$ atoms, which enable it to make H-bonding with chitosan (see Scheme 1(b)) $[19,20]$. It is well known that the hydrogen bonding as secondary forces is much weaker than the primary bond within the molecules, such as covalent bonds and other polar bonds, but much stronger than the van der Waals interaction [9]. The broadness of the X-ray peak for the CS:POZ blend would indicate that interchain spacing in the blend sample is larger than that of the individual polymers. The expanded interchain spacing in the blend makes dipole reorientation to the applied field much easier, resulting in a higher dielectric constant compared with that of the neat polymers [10]. From dielectric analysis, one can receive more insights into the role of polymer blending on electrical properties.

3.2. Morphological Study. The optical microscope (OM) images for the CS:POZ blend films are presented in Figure 3. Recent studies confirmed that whenever two polymers are blended, different morphologies, such as spherulite and lamellar may appear as a consequence of synergic effect. It depends upon the degree of miscibility of polymers with each other [28]. From the literature survey, it is clearly observed that the dark and brilliant region may appear in OM images as a result of the structural behaviour of the blend films. The dark regions are attributed to amorphous phases, whereas the radiant phases or spherulites relate to crystalline areas [13]. The present work revealed that the $\mathrm{OM}$ technique has shown a powerful ability to observe the structural change which occurs in polymer composites and polymer blend systems $[3,13,29]$. It also revealed that the OM technique is capable of detecting the neutral silver particles in chitosan-based polymer electrolytes via the appearance of brilliant white spots or white chains on the polymer surface $[3,13]$. The close inspection at adjusted magnification (274.3) indicates that the spherulites due to amorphous phase cover the surface and small brilliant regions ascribed to the crystalline area also appeared. Interestingly, at $15 \mathrm{wt} . \% \mathrm{POZ}$, the dark regions and distinguishable brilliant phases ascribed to amorphous and crystalline phases appear. To identify, the OM technique has been used to observe the crystalline and amorphous phases in PEO-based composites [13]. From the earlier studies, the brilliant spherulites are due to the crystalline structure, and the dark regions correspond to the amorphous phase. It is also shown that the dark boundaries between the spherulites are usually owing to the existence of an amorphous phase $[13,30]$. However, in the current work, it is confirmed that the brilliant and dark regions of the spherulites are correlated to a crystalline and amorphous domain, respectively. Previous studies confirmed that the almost crystalline nature of PEO is responsible for many spherulites in CS:PEO-based electrolytes and little dark regions $[3,13]$. In contrast to earlier studies $[3,13,30]$, the dark spherulites appeared in $\mathrm{OM}$ images are ascribed to amorphous domains, and the little brilliant phases are attributed to crystalline regions. Compared to our previous work [29], POZ is more compatible with CS rather than PVA. In our earlier work, many brilliant phases due to crystallinity enhancement in the PVA:POZ polymer blend were observed. The explanation is in accordance with XRD results. Ultimately, it seems that the results obtained in the OM technique analysis and XRD patterns support each other.

3.3. Dielectric and Electric Modulus Study. The local mobility and nature of the polymer-polymer interactions can be investigated through dielectric relaxation [31]. Recent studies have revealed that there are several methods for 


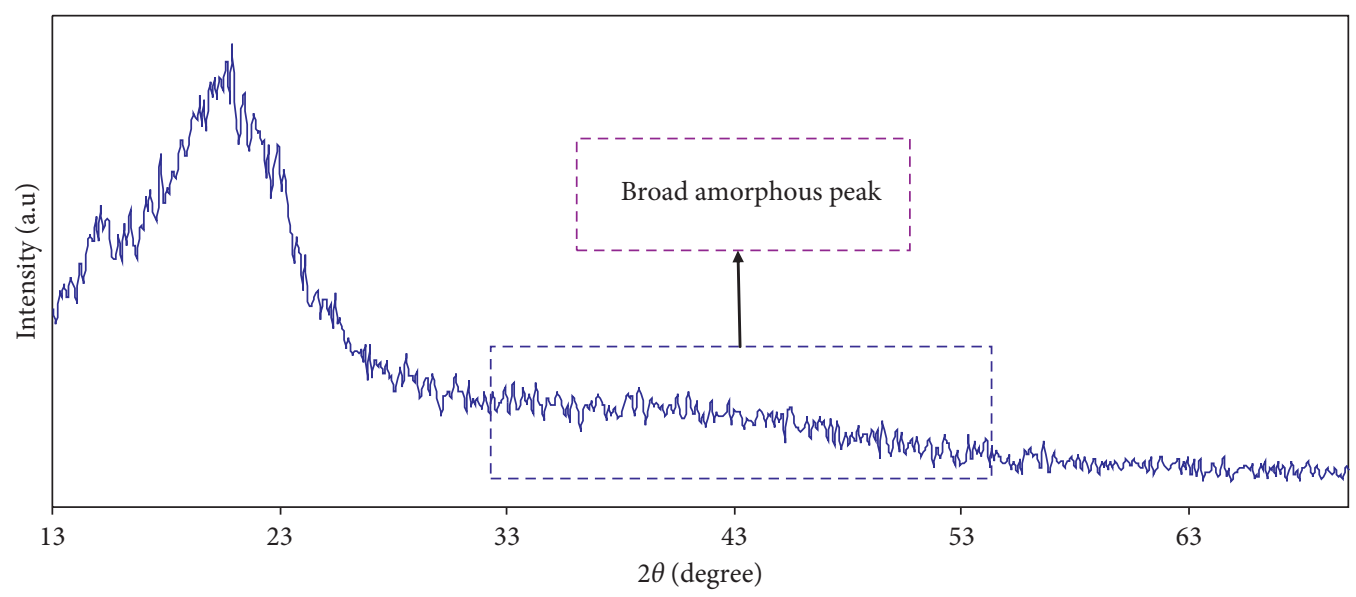

FIGURE 1: XRD pattern for the pure chitosan (CS) film.

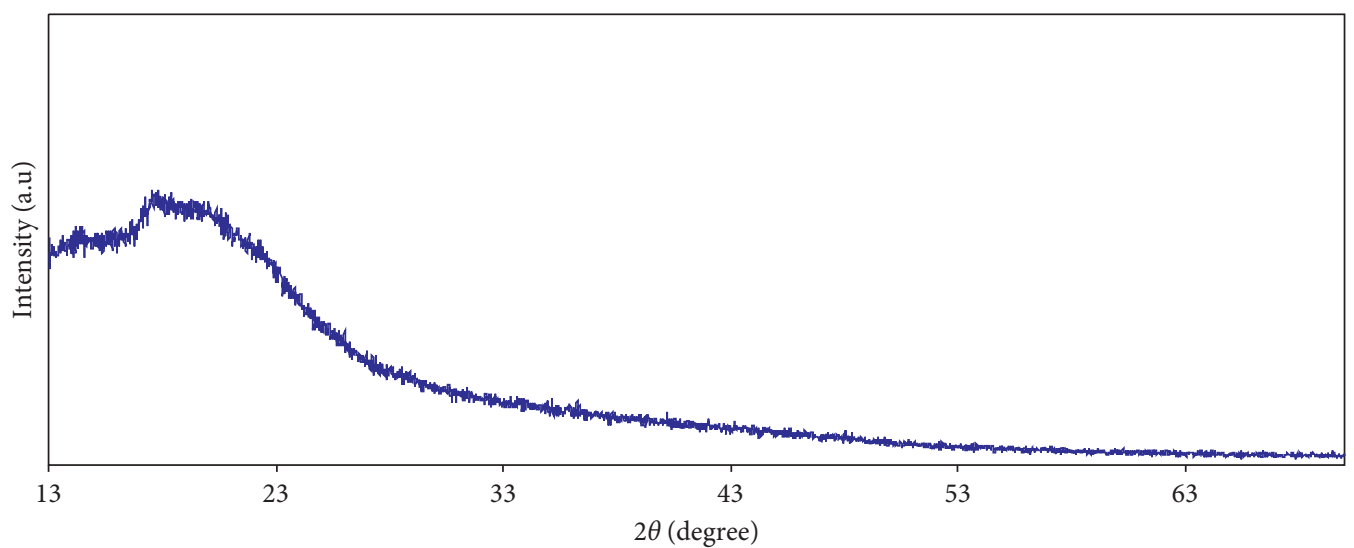

(a)

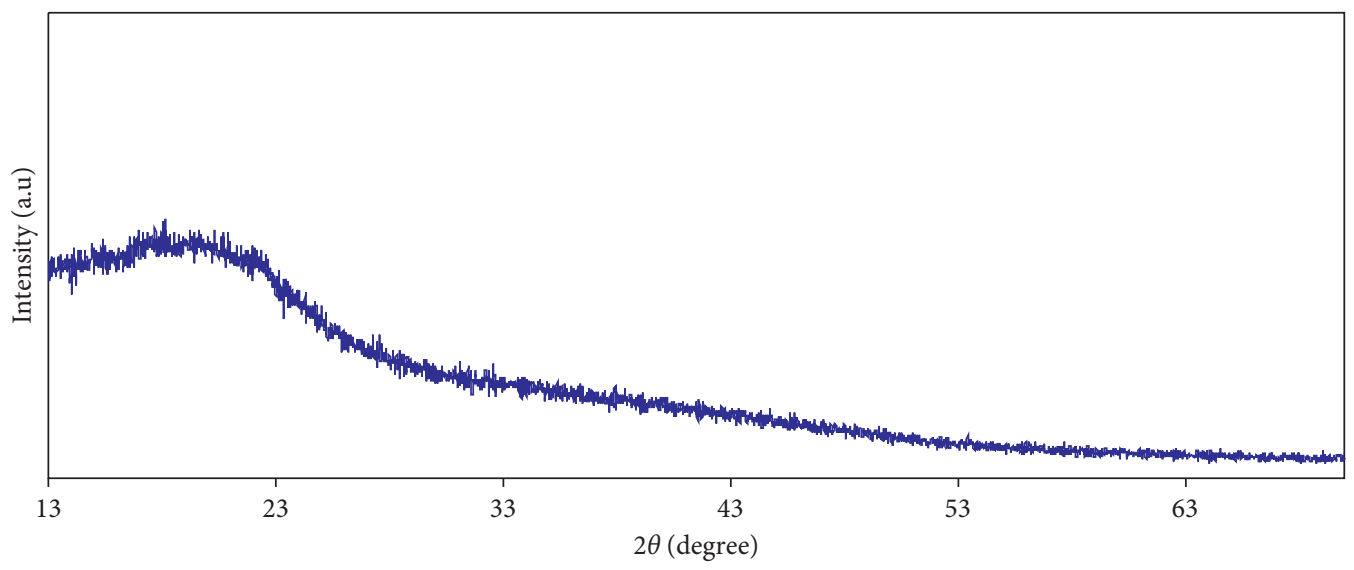

(b)

FIGURE 2: XRD pattern for chitosan incorporated with (a) 15 wt. $\%$ and (b) 45 wt.\% of POZ.

characterizing dielectric material properties, such as microwave reflection coefficient, relative permittivity and loss tangent, split postdielectric resonance technique, port coaxial and waveguide cells, open-ended probes, and terahertz $(\mathrm{THz})$ metamaterials in the $\mathrm{THz}$ frequency ranges. During recent years, a lot of research activities have been conducted in the aiming of improving the accuracy and sensitivity of material characterization [32-36]. In particular, impedance measurements at various frequencies are found to be an accurate method to study the molecular motion of dielectric materials at different temperatures $[29,36]$. Here, in the following, investigation of the dielectric properties of the material has been conducted which plays a vital role in directing the suitable applications [37]. From the real $\left(Z^{\prime}\right)$ 
<smiles>CCC(C)CN(CC)C(C)C</smiles>

(a)

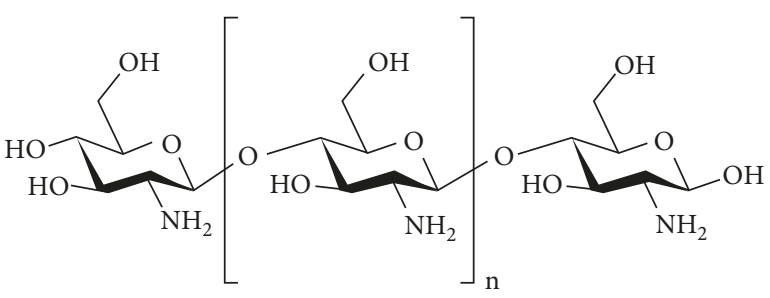

(b)

Scheme 1: Molecular structure of (a) POZ and (b) CS polymers.

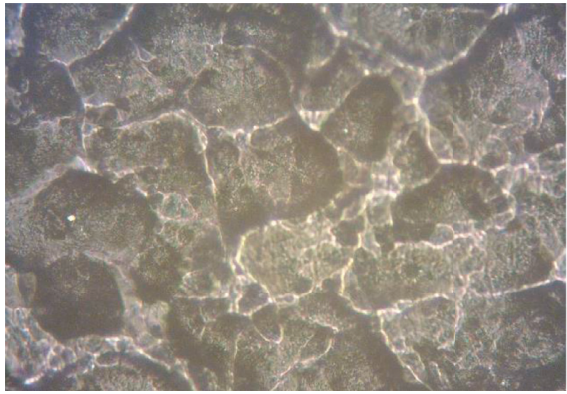

(a)

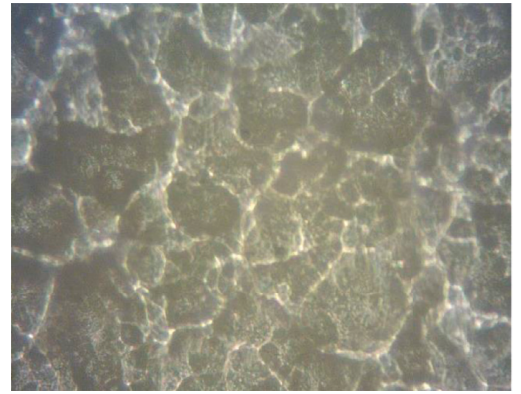

(b)

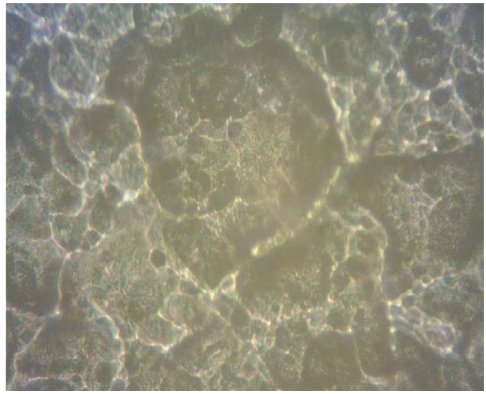

(c)

FIgURE 3: Optical microscope images for (a) PBS1, (b) PBS2, and (c) PBS3 films.

and imaginary $\left(Z^{\prime \prime}\right)$ part of complex impedance $\left(Z^{*}\right)$, the permittivity $\left(\varepsilon^{*}\right)$ of both axes was calculated using the following relations [38]:

$$
\begin{aligned}
\varepsilon^{\prime} & =\frac{Z^{\prime}}{\omega C_{o}\left(Z^{\prime 2}+Z^{\prime \prime 2}\right)}, \\
\varepsilon^{\prime \prime} & =\frac{Z^{\prime \prime}}{\omega C_{o}\left(Z^{\prime 2}+Z^{\prime 2}\right)}, \\
\tan \delta & =\frac{Z^{\prime}}{Z^{\prime \prime}},
\end{aligned}
$$

where $C_{o}$ indicates the vacuum capacitance of the cell from $\varepsilon_{o} A / t$ (where $t$ and $A$ refer to the thickness and area of the film, respectively) and $\omega=2 \pi f$ is the angular frequency, $f$ is the frequency in hertz. Figures 4 and 5 reveal the frequency dependence of $\varepsilon^{\prime}$ and $\varepsilon^{\prime \prime}$ for all the blend films. On the one hand, it is interesting to notice that at $15 \mathrm{wt} . \%$ of POZ, the dielectric parameters $\left(\varepsilon^{\prime}\right.$ and $\left.\varepsilon^{\prime \prime}\right)$ exhibit high values, and on the other hand, at the higher concentration, a drop in dielectric values can be observed. This optimization of dielectric parameters at $15 \mathrm{wt} . \%$ may be attributed to the increases of functional groups in CS:POZ films, resulting in enhanced dipolar polarisation at the interfacial region of the blends [39]. The high values of $\varepsilon^{\prime}$ and $\varepsilon^{\prime \prime}$ may be correlated to the interfacial structure at the bulk and the electrode region of the sample $[31,37]$. The accumulation of a massive quantity of charge carriers at the electrode/ electrolyte interfacial region generates electrode polarisation, which in turn suppresses the high-frequency

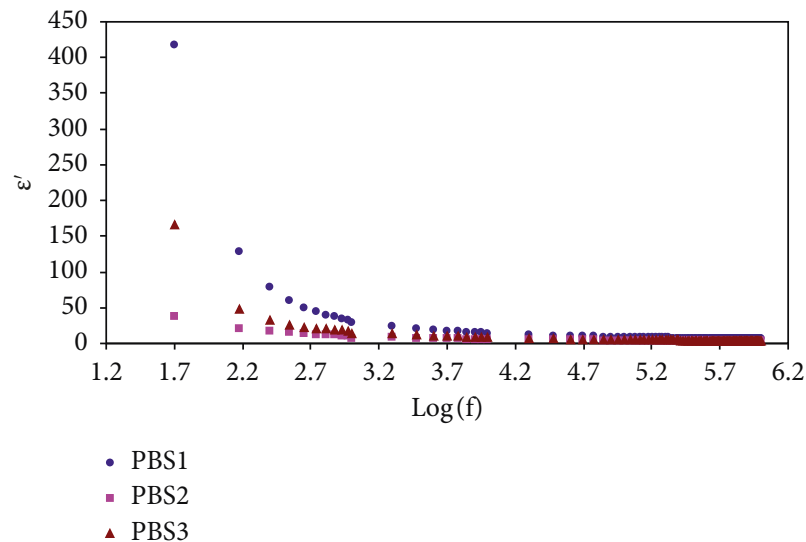

Figure 4: Dielectric constant versus frequency at ambient temperature for CS:POZ blend samples.

dielectric values (bulk property) $[18,38]$. This polarity in these materials produces relatively high initial values for both $\varepsilon^{\prime}$ and $\varepsilon^{\prime \prime}$, but as the frequency of the field is increased, the value starts to drop as a consequence of the dipoles that are not able to follow the field variation [37]. In other words, the slow orientation of polar groups of CS:POZ polymer blends, compared to the variations of the electric field at the higher frequency, leads to a plateau region appearance in the $\varepsilon$ spectra [40].

The temperature dependent of $\varepsilon^{\prime}$ and $\varepsilon^{\prime \prime}$ is shown in Figures 6 and 7. Both of them increase with increasing temperature. Apparently, the correlation of dielectric permittivity and temperature is different for polar and nonpolar 


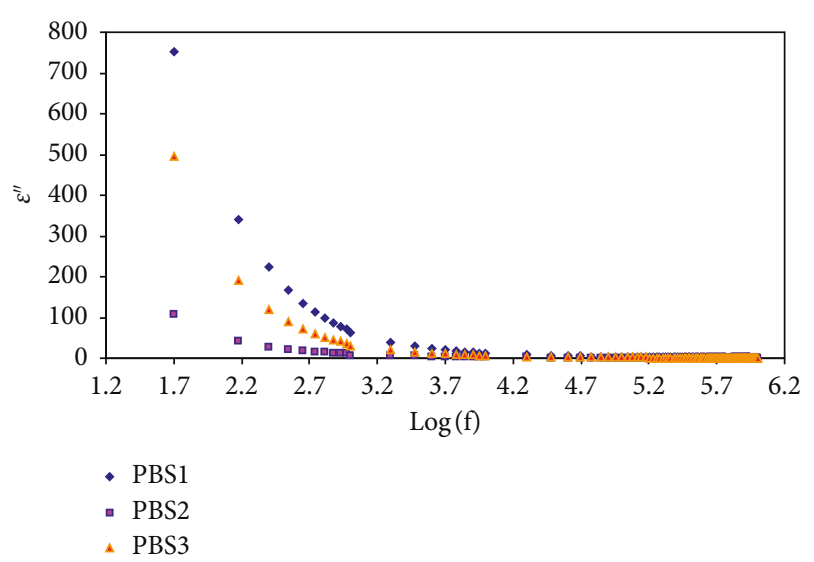

FIgURE 5: Dielectric loss versus frequency at ambient temperature for CS:POZ blend samples.

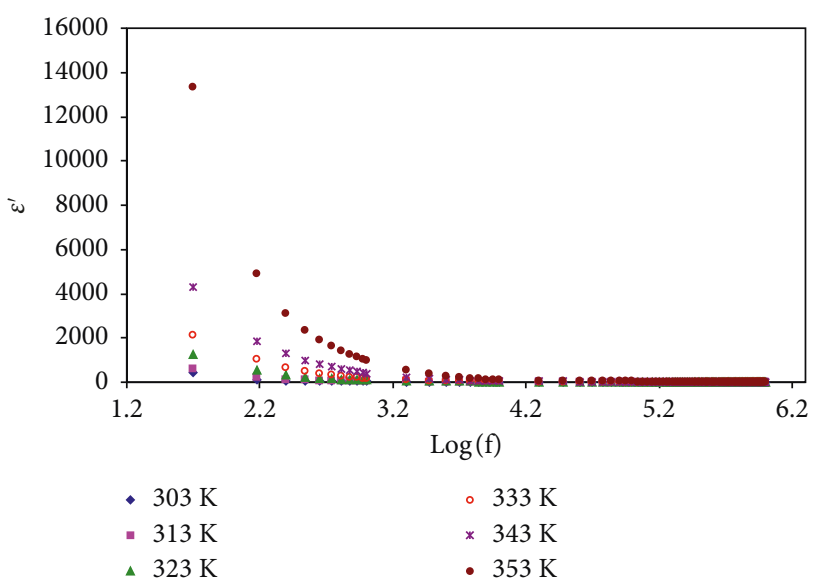

Figure 6: Dielectric constant versus frequency at various temperatures for the PBS1 blend sample.

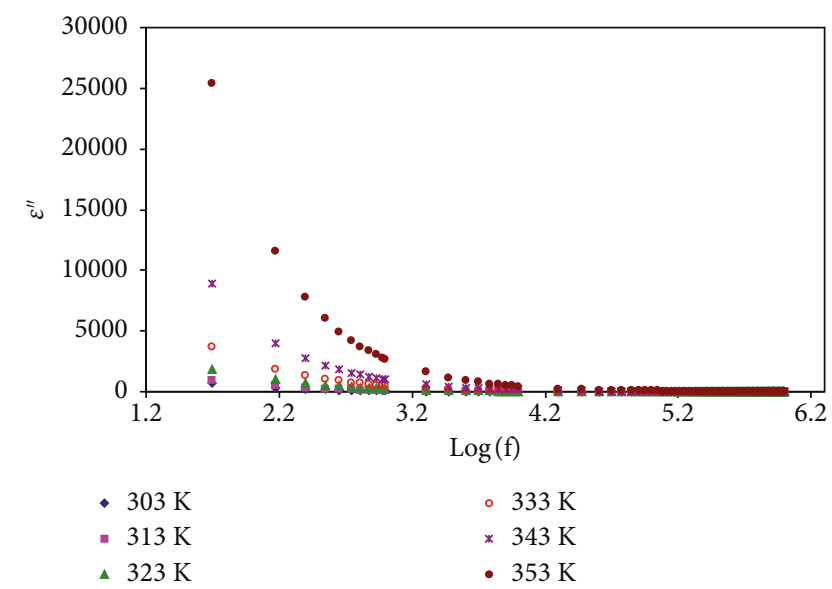

FIGURE 7: Dielectric loss versus frequency at various temperatures for the PBS1 blend sample.

polymers. Indeed, there is a direct proportionality between the dielectric permittivity and temperature for polar polymers. However, for nonpolar polymers, the dielectric permittivity is independent of temperature. This behaviour is considered as a characteristic for polar dielectrics in which the orientation of dipoles is facilitated with rising temperature and thereby the permittivity is increased [41]. From all these, it is clearly seen that the dielectric loss values are greater than those of dielectric constant. To be a complementary study, it is worth noting that the value of dielectric loss is greater than that of dielectric constant, and there are no apparent peaks that can be seen in dielectric loss spectra. Obviously, the dielectric data are distinguishable by superposition of two processes: the conductivity contribution and the relaxation process. The conductivity contribution signifies both the real part $\varepsilon^{\prime}$ and the imaginary part $\varepsilon^{\prime \prime}$ of the dielectric function on a declining frequency and a relaxation process exhibiting a maximum in $\varepsilon^{\prime \prime}$ which shifts to a higher frequency side with increasing temperatures. Thus, the measured $\varepsilon^{\prime \prime}$ spectrum comprises contribution from two sources: dipolar orientation and diffusion of the charge carrier [30]; consequently, the peaks are hidden in $\varepsilon^{\prime \prime}$ spectra as can be seen in Figure 7. In common usage, a conduction-induced relaxation acts in a manner of $\varepsilon^{\prime \prime}=\sigma_{d c} / 2 \pi f$, where $\sigma_{d c}$ and $f$ denote the direct current electrical conductivity and frequency, respectively. Furthermore, the electrical conduction cannot be related to the dielectric enhancement since the former is unable to store electrical energy [39]. Thus, the high dielectric loss value in comparison to dielectric constant can be attributed to the contribution of DC conductivity.

Both relaxation frequency and relaxation time $(\tau)$ processes are important, where the latter is a parameter that depends only upon the intrinsic properties of materials rather than the sample geometrical factors. The intrinsic properties of the materials refer to the properties that are attributed to the microstructure [42]. The $\tan \delta$ spectra for the blend samples are presented in Figure 8 at ambient temperature. From the figure, the existence of dielectric relation process is evidenced from the tangent loss peaks and their shift with POZ at different concentrations [43]. In polymers with appreciable electrical conductivity, dielectric relaxation peaks caused by permanent or induced dipoles may be hidden by the relaxation. This results from polarisation of mobile-charged species present in the material, and thus, the low-frequency relaxation peaks are usually obscured in $\varepsilon^{\prime \prime}$ spectra as depicted in Figures 5 and 7. However, the peak appearance in $\tan \delta$ spectra is correlated to the fact that electrode polarisation decreases in $\tan \delta$ representation [44]. Thus, small hidden peaks in $\varepsilon^{\prime \prime}$ spectra amplify in $\tan \delta$ spectra. From Figure 8, the $\tan \delta$ shape can be interpreted in terms of Koops phenomenological model [45]. Accordingly, the loss tangent increases with increase in frequency, showing a maximum at particular frequencies because the ohmic component of the current (faradaic current) increases more rapidly than its capacitive one. On the one hand, at the higher frequencies, loss tangent decreases with an increase in frequency as a result of the ohmic component of current which is practically frequency independent. On the other hand, the capacitive component $\left(X_{c}=1 / 2 \pi f C\right)$ increases proportionally with frequency $[45,46]$. The broadness of the loss tangent peak emphasises the fact that the relaxation process obeys non-Debye relaxation. Figure 9 shows the variation of $\tan \delta$ with frequency 


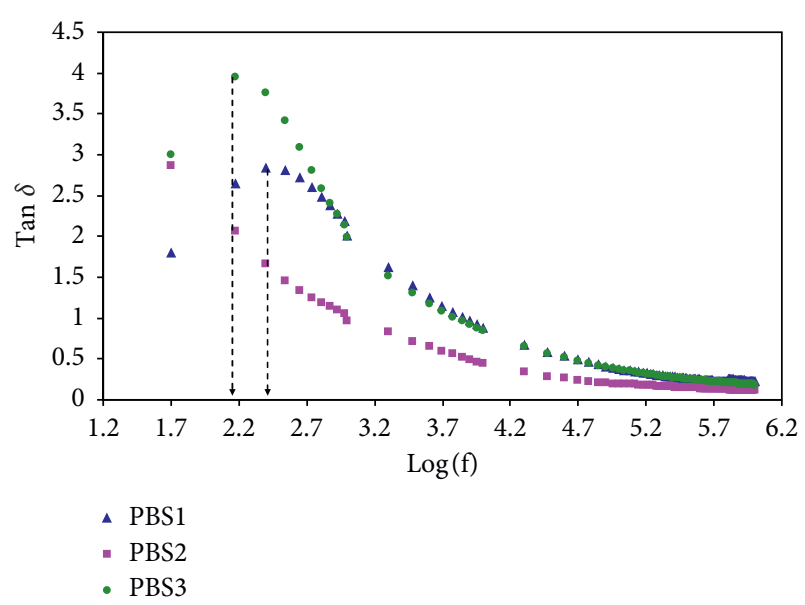

Figure 8: Loss tangent $(\tan \delta)$ versus frequency at ambient temperature for CS:POZ blend samples.

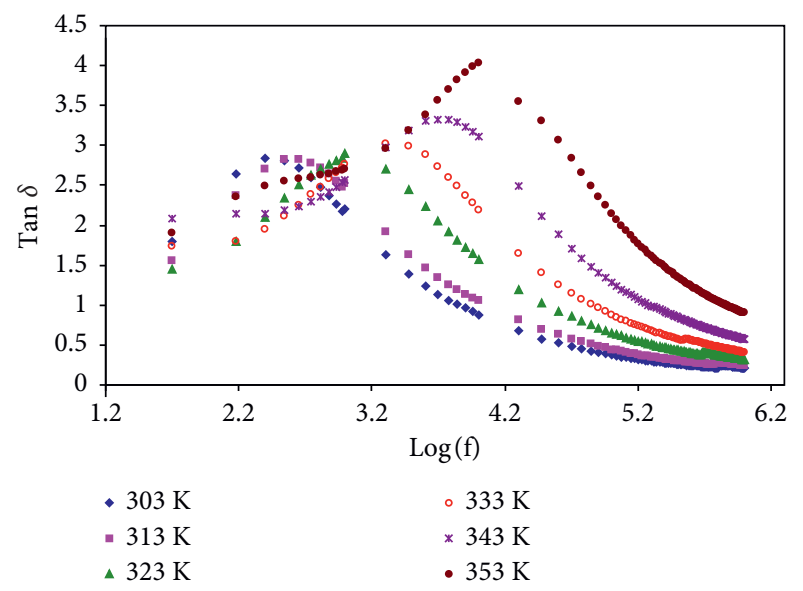

FIgURE 9: Loss tangent $(\tan \delta)$ versus frequency at selected temperatures for the PBS3 blend sample.

at different temperatures. The whole peak position shifts uniformly towards higher frequency as temperature increases. This ensures the temperature dependence of the relaxation process in the sample. This shift in peak positions towards the higher frequency whenever the temperature is raised can likely be attributed to the lowering of the bulk resistivity of the whole sample. The viscosity of the polymer started to decrease slightly due to an increase in temperature, particularly beyond $288 \mathrm{~K}$, resulting in an ease of rotation of dipole with the field and a slight increase in dielectric constant [47]. The asymmetric peak behaviour suggests the presence of electrical processes in the material with the spread out of relaxation time [48]. Moreover, the increase in peak height of $\tan \delta$ with temperature could be associated to the decrease in resistivity of the sample [49].

The study of the dielectric relaxation phenomena is considered an extremely useful way of understanding molecular interaction in solid polymer electrolytes and blends [30]. It is well reported that there are two relaxation processes in polymeric materials: viscoelastic relaxation and

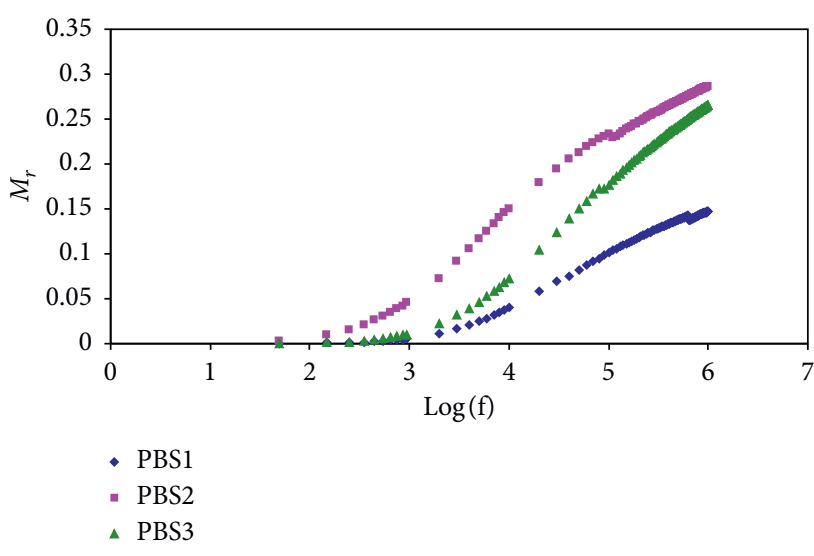

FIgURE 10: Real part $\left(M_{r}\right)$ of electric modulus versus frequency at ambient temperature for CS:POZ blend samples.

conductivity relaxation. The former is due to the dipolar relaxation due to the existence of permanent dipoles on the side chains of the polymer backbone, whereas the latter results from the translational diffusion of free carriers which are responsible for the ion conduction [50]. Indeed, both real and imaginary parts of complex electric modulus $\left(M^{*}\right)$ were calculated from the impedance using the following relations $[51,52]$ :

$$
\begin{aligned}
& M_{r}=\frac{\varepsilon^{\prime}}{\left(\varepsilon^{\prime 2}+\varepsilon^{\prime \prime 2}\right)}=\omega C_{o} Z^{\prime \prime} \\
& M_{i}=\frac{\varepsilon^{\prime \prime}}{\left(Z^{\prime 2}+\varepsilon^{\prime \prime 2}\right)}=\omega C_{o} Z^{\prime} .
\end{aligned}
$$

Figures 10 and 11 show the $M_{r}$ and $M_{i}$ spectra at ambient temperature. On the one hand, in $M_{r}$ spectra, the value of $M_{r}$ is quite close to zero at the low frequency as a consequence of the high electrode polarisation as observed in $\varepsilon^{\prime}$ spectra as presented in Figure 4 . On the other hand, in $M_{i}$ spectra, apparent peaks are seen which is related to the relaxation phenomena of free carriers or chain orientation in the blend samples. In a meaningful view, the asymmetric behaviour of the peaks can likely be attributed to the distribution of relaxation time [53]. The reorientation process of dipoles in the polymer chains results in dielectric relaxation, showing a peak in $\varepsilon^{\prime \prime}$ spectra. It is well known that the perturbation of the electric charge results from the movement of charge carriers. Likewise, other charge carriers in this region will be affected by potential perturbation. This cooperative motion of ions obeys nonexponential decay or the conduction processes with distribution of relaxation time $[30,54]$. Thus, the hidden peaks in $\varepsilon^{\prime \prime}$ spectra are ascribed to the contribution of DC conductivity and electrode polarisation. A recent advanced study shows small values of $M_{r}$ and $M_{i}$ at lower frequencies indicating the exclusion of electrode polarisation involvement in the electric modulus study $[1,3]$.

For blend films, the variation of $M_{r}$ and $M_{i}$ values with frequencies at various temperatures is presented in Figures 12 and 13. From these, one can see that a peak signifies 


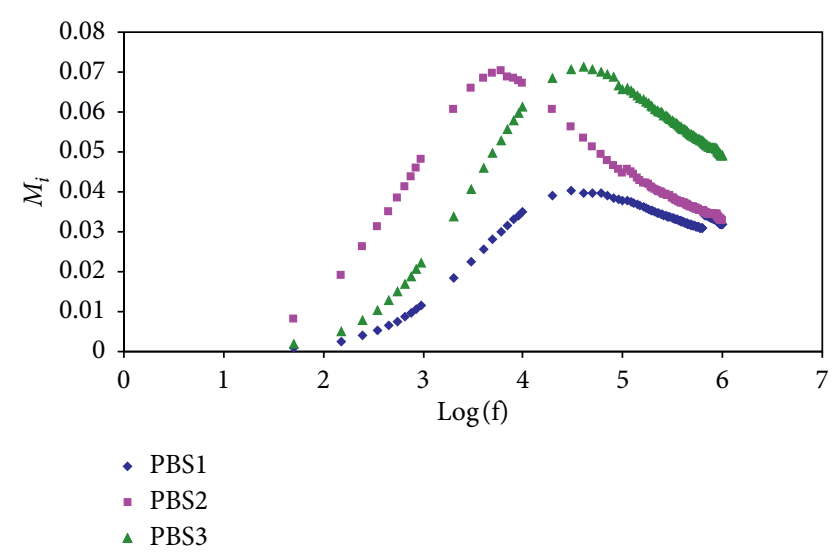

FIGURE 11: Imaginary part $\left(M_{i}\right)$ of electric modulus versus frequency at ambient temperature for CS:POZ blend samples.

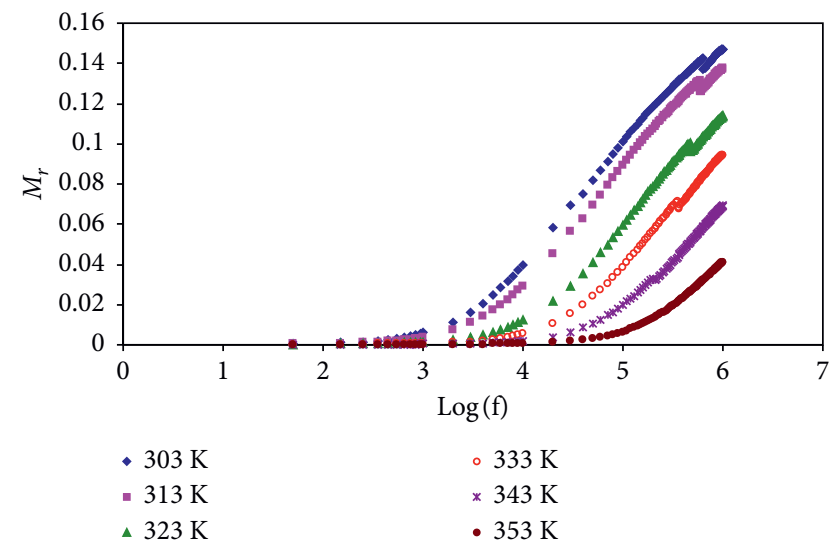

FIGURE 12: Real part $\left(M_{r}\right)$ of electric modulus versus frequency at selected temperatures for the PBS3 blend sample.

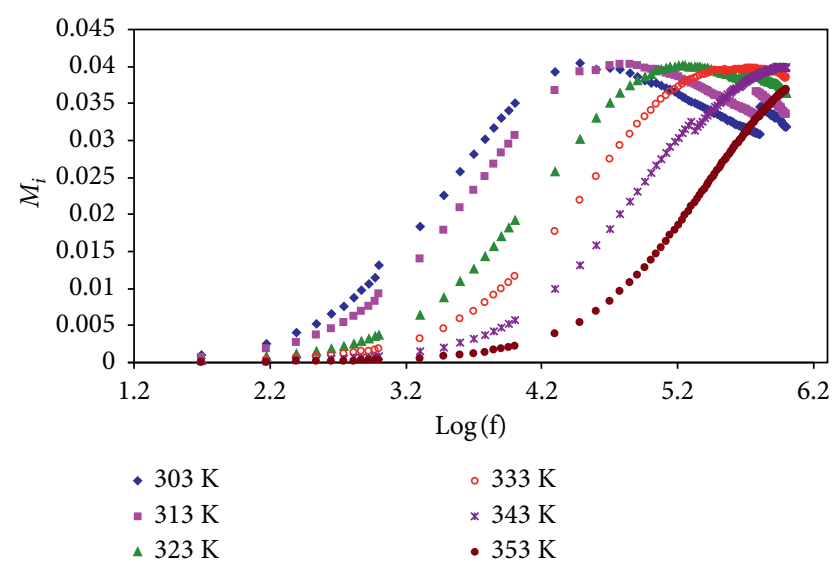

FIGURE 13: Imaginary part $\left(M_{i}\right)$ of electric modulus versus frequency at selected temperatures for the PBS3 blend sample.

the relaxation process at the higher temperatures. The peak shifting towards the higher frequency region with an increase in temperature occurs as a consequence of relaxation time decreasing. This can be due to the thermally activated charge carrier at the high temperatures [47]. At first glance, the right and left sides of the $M_{i}$ frequency peaks represent the charge carriers that are spatially confined to the potential wells and those that are mobile over a long distance, respectively. The frequency range over the peak base is indicative of the transition from long-range to short-range mobility by increasing frequency of the applied electric field [55].

\section{Conclusions}

In conclusion, it seems that polymer blending is a reasonable methodology in designing a desired polymer for electronics. The relatively high dielectric constant blend polymer can be obtained from mixing up to $15 \mathrm{wt} . \%$ of poly(2-ethyl-2oxazoline), (POZ), with chitosan (CS). An increase in dielectric constant of the blend polymer from incorporation of $\mathrm{POZ}$ into CS at the desired concentration and a decrease at higher concentration were observed. This is also confirmed from the structural study where the peak broadening was observed as a result of POZ incorporation at the optimum concentration. The optical micrograph showed clearly the amorphous and the crystalline regions over the whole polymer structure which are seen from their dark and brilliant appearance, respectively.

From the impedance analysis, the dielectric constant and dielectric loss were found to increase with increasing the temperature because of enhancement of polarisation. The loss tangent peak of most amorphous samples was observed at the high-frequency region. The increase of $\mathrm{POZ}$ concentration to $45 \mathrm{wt} . \%$ makes the loss tangent shift to the lower frequency region which is attributable to the increase of crystallinity. The loss tangent peaks are found to shift to the higher frequency region with an increase in temperature. Obvious relaxation peaks were observed in the imaginary parts of the electric modulus, and no peaks were found in the dielectric loss spectra. The concentration dependent of $M^{\prime \prime}$ peaks was emphasised to obey the same trend of loss tangent peaks versus POZ content, and the relaxation process was studied in terms of electric modulus parameters.

\section{Data Availability}

The data used to support the findings of this study are included within the article.

\section{Conflicts of Interest}

The authors declare that they have no conflicts of interest.

\section{Acknowledgments}

The authors gratefully acknowledge the financial support for this study from the Ministry of Higher Education and Scientific Research, the Kurdish National Research Council (KNRC), and the Kurdistan Regional Government, Iraq. The financial support from the University of Sulaimani, Komar Research Center (KRC), and Komar University of Science and Technology is greatly appreciated. 


\section{References}

[1] S. B. Aziz and S. M. Mamand, "The study of dielectric properties and conductivity relaxation of ion conducting chitosan:NaTf based solid electrolyte," International Journal of Electrochemical Science, vol. 13, pp. 10274-10288, 2018.

[2] N. Ignjatović, V. Wu, Z. Ajduković, T. Mihajilov-Krstev, V. Uskoković, and D. Uskoković, "Chitosan-PLGA polymer blends as coatings for hydroxyapatite nanoparticles and their effect on antimicrobial properties, osteoconductivity and regeneration of osseous tissues," Materials Science and Engineering C, vol. 60, pp. 357-364, 2016.

[3] S. B. Aziz, R. M. Abdullah, M. F. Z. Kadir, and H. M. Ahmed, "Non suitability of silver ion conducting polymer electrolytes based on chitosan mediated by barium titanate $\left(\mathrm{BaTiO}_{3}\right)$ for electrochemical device applications," Electrochimica Acta, vol. 296, pp. 494-507, 2019.

[4] S. B. Aziz, R. T. Abdulwahid, M. H. Hamsan et al., "Structural, impedance, and EDLC characteristics of proton conducting chitosan-based polymer blend electrolytes with high electrochemical stability," Molecules, vol. 24, no. 19, p. 3508, 2019.

[5] T. Blensdorf, A. Joenathan, M. Hunt et al., "Hybrid composite polymer electrolytes: ionic liquids as a magic bullet for the poly(ethylene glycol)-silica network," Journal of Materials Chemistry A, vol. 5, no. 7, pp. 3493-3502, 2017.

[6] J. Shim, D.-G. Kim, H. J. Kim, J. H. Lee, J.-H. Baik, and J.-C. Lee, "Novel composite polymer electrolytes containing poly(ethylene glycol)-grafted graphene oxide for all-solidstate lithium-ion battery applications," Journal of Materials Chemistry A, vol. 2, no. 34, pp. 13873-13883, 2014.

[7] E. A. El-Hefian, M. M. Nasef, and A. H. Yahaya, "Chitosanbased polymer blends: current status and applications," Journal of the Chemical Society of Pakistan, vol. 36, no. 1, pp. 11-27, 2014.

[8] M. Mucha, J. Piekielna, and A. Wieczorek, "Characterisation and morphology of biodegradable chitosan/synthetic polymer blends," Macromolecular Symposia, vol. 144, no. 1, pp. 391-412, 1999.

[9] Y. He, B. Zhu, and Y. Inoue, "Hydrogen bonds in polymer blends," Progress in Polymer Science, vol. 29, no. 10, pp. 1021-1051, 2004.

[10] Y. Thakur, B. Zhang, R. Dong et al., "Generating high dielectric constant blends from lower dielectric constant dipolar polymers using nanostructure engineering," Nano Energy, vol. 32, pp. 73-79, 2017.

[11] F. Piana, J. Kredatusova, B. Paruzel, and J. Pfleger, "Polymer blends of poly(2-cyanoethyl vinyl ether) and poly(methyl methacrylate) with improved dielectric properties for flexible electronics," Express Polymer Letters, vol. 11, no. 9, pp. 731-737, 2017.

[12] M. F. Z. Kadir, Z. Aspanut, S. R. Majid, and A. K. Arof, "FTIR studies of plasticized poly(vinyl alcohol)-chitosan blend doped with $\mathrm{NH}_{4} \mathrm{NO}_{3}$ polymer electrolyte membrane," Spectrochimica Acta Part A: Molecular and Biomolecular Spectroscopy, vol. 78, no. 3, pp. 1068-1074, 2011.

[13] S. B. Aziz and R. M. Abdullah, "Crystalline and amorphous phase identification from the $\tan \delta$ relaxation peaks and impedance plots in polymer blend electrolytes based on [CS: AgNt $] x$ : $\operatorname{PEO}(x-1)(10 \leq x \leq 50)$," Electrochimica Acta, vol. 285 , pp. $30-46,2018$.

[14] Siddaramaiah, P. Kumar, K. H. Divya, B. T. Mhemavathi, and D. S. Manjula, "Chitosan/HPMC polymer blends for developing transdermal drug delivery systems," Journal of Macromolecular Science, Part A, vol. 43, no. 3, pp. 601-607, 2006.
[15] A. Isogai and R. H. Atalla, "Preparation of cellulose-chitosan polymer blends," Carbohydrate Polymers, vol. 19, no. 1, pp. 25-28, 1992.

[16] G. K. Abilova, D. B. Kaldybekov, E. K. Ozhmukhametova et al., "Chitosan/poly(2-ethyl-2-oxazoline) films for ocular drug delivery: formulation, miscibility, in vitro and in vivo studies," European Polymer Journal, vol. 116, pp. 311-320, 2019.

[17] A. Shubha, S. R. Manohara, and L. Gerward, "Influence of polyvinylpyrrolidone on optical, electrical and dielectric properties of poly(2-ethyl-2-oxazoline)- polyvinylpyrrolidone blends," Journal of Molecular Liquids, vol. 247, pp. 328-336, 2017.

[18] S. B. Aziz, " $\mathrm{Li}^{+}$ion conduction mechanism in poly ( $\varepsilon$-caprolactone)-based polymer electrolyte," Iranian Polymer Journal, vol. 22, no. 12, pp. 877-883, 2013.

[19] L. Ruiz-Rubio, M. Alonso, L. Pérez-Álvarez, R. Alonso, J. Vilas, and V. Khutoryanskiy, "Formulation of carbopol ${ }^{\circledR} / \operatorname{poly}(2$ ethyl-2-oxazoline)s mucoadhesive tablets for buccal deliveryof hydrocortisone," Polymers, vol. 10, no. 2, p. 175, 2018.

[20] R. W. Moreadith, T. X. Viegas, M. D. Bentley et al., "Clinical development of a poly(2-oxazoline) (POZ) polymer therapeutic for the treatment of Parkinson's disease-proof of concept of POZ as a versatile polymer platform for drug development in multiple therapeutic indications," European Polymer Journal, vol. 88, pp. 524-552, 2017.

[21] S. B. Aziz, "Occurrence of electrical percolation threshold and observation of phase transition in chitosan(1-x):AgIx $(0.05 \leq x \leq 0.2)$-based ion-conducting solid polymer composites," Applied Physics A, vol. 122, no. 7, p. 706, 2016.

[22] K. Sakurai, T. Maegawa, and T. Takahashi, "Glass transition temperature of chitosan and miscibility of chitosan/poly(Nvinyl pyrrolidone) blends," Polymer, vol. 41, no. 19, pp. 7051-7056, 2000.

[23] R. Le Goff, G. Poutot, D. Delaunay, R. Fulchiron, and E. Koscher, "Study and modeling of heat transfer during the solidification of semi-crystalline polymers," International Journal of Heat and Mass Transfer, vol. 48, no. 25-26, pp. 5417-5430, 2005.

[24] S. León, J. J. Navas, and C. Alemán, “PCSP: a computer program to predict and analyze the packing in crystalline polymers," Polymer, vol. 40, no. 26, pp. 7351-7358, 1999.

[25] S. B. Aziz, Z. H. Z. Abidin, and A. K. Arof, "Effect of silver nanoparticles on the DC conductivity in chitosan-silver triflate polymer electrolyte," Physica B: Condensed Matter, vol. 405, no. 21, pp. 4429-4433, 2010.

[26] C. G. A. Lima, R. S. de Oliveira, S. D. Figueiró, C. F. Wehmann, J. C. Góes, and A. S. B. Sombra, "DC conductivity and dielectric permittivity of collagen-chitosan films," Materials Chemistry and Physics, vol. 99, no. 2-3, pp. 284-288, 2006.

[27] H. Fael, C. Ràfols, and A. L. Demirel, "Poly(2-Ethyl-2-Oxazoline) as an alternative to poly(vinylpyrrolidone) in solid dispersions for solubility and dissolution rate enhancement of drugs," Journal of Pharmaceutical Sciences, vol. 107, no. 9, pp. 2428-2438, 2018.

[28] A. H. A. Razak, P. Szaboa, and A. L. Skov, "Enhancement of dielectric permittivity by incorporating PDMS-PEG multiblock copolymers in silicone elastomers," RSC Advances, vol. 5, no. 65, pp. 53054-53062, 2015.

[29] S. B. Aziz, M. F. Z. Kadir, M. H. Hamsan, H. J. Woo, and M. A. Brza, "Development of polymer blends based on PVA: POZ with low dielectric constant for microelectronic applications," Scientific Reports, vol. 9, no. 1, p. 13163, 2019. 
[30] D. K. Pradhan, R. N. P. Choudhary, and B. K. Samantaray, "Studies of dielectric relaxation and AC conductivity behavior of plasticized polymer nanocomposite electrolytes," International Journal of Electrochemical Science, vol. 3, pp. 597608, 2008.

[31] O. V. Khutoryanskaya, V. V. Khutoryanskiy, and R. A. Pethrick, "Characterisation of blends based on hydroxyethylcellulose and maleic acid-alt-methyl vinyl ether," Macromolecular Chemistry and Physics, vol. 206, no. 15, pp. 1497-1510, 2005.

[32] N. Chudpooti, V. Doychinov, B. Hong, P. Akkaraekthalin, I. Robertson, and N. Somjit, "Multi-modal millimeter-wave sensors for plastic polymer material characterization," Journal of Physics D: Applied Physics, vol. 51, no. 27, Article ID 275103, 2018.

[33] A. N. AL-Omari and K. L. Lear, "Dielectric characteristics of spin-coated dielectric films using on-wafer parallel-plate capacitors at microwave frequencies," IEEE Transactions on Dielectrics and Electrical Insulation, vol. 12, pp. 1151-1161, 2005.

[34] S. J. Park, S. A. N. Yoon, and Y. H. Ahn, "Dielectric constant measurements of thin films and liquids using terahertz metamaterials," RSC Advances, vol. 6, no. 73, pp. 69381-69386, 2016.

[35] L. Anderson and M. Jacob, "Microwave characterization of a novel, environmentally friendly, plasma polymerized organic thin film," Physics Procedia, vol. 14, pp. 87-90, 2011.

[36] S. B. Aziz, S. M. Mamand, S. R. Saed, R. M. Abdullah, and S. A. Hussein, "New method for the development of plasmonic metal-semiconductor interface layer: polymer composites with reduced energy band gap," Journal of Nanomaterials, vol. 2017, Article ID 8140693, 9 pages, 2017.

[37] H. M. Zidan, N. A. El-Ghamaz, A. M. Abdelghany, and A. Lotfy, "Structural and electrical properties of PVA/PVP blend doped with methylene blue dye," International Journal of Electrochemical Science, vol. 11, pp. 9041-9056, 2016.

[38] S. B. Aziz and Z. H. Z. Abidin, "Ion-transport study in nanocomposite solid polymer electrolytes based on chitosan: electrical and dielectric analysis," Journal of Applied Polymer Science, vol. 132, no. 15, p. 41774, 2015.

[39] Z. Chen, Y. Liu, L. Fang, P. Jiang, and X. Huang, "Role of reduced graphene oxide in dielectric enhancement of ferroelectric polymers composites," Applied Surface Science, vol. 470, pp. 348-359, 2019.

[40] Z. Chen, J. Pei, and R. Li, "Study of the preparation and dielectric property of PP/SMA/PVDF blend material," Applied Sciences, vol. 7, no. 4, p. 389, 2017.

[41] A. R. Polu and R. Kumar, "AC impedance and dielectric spectroscopic studies of $\mathrm{Mg}^{2+}$ ion conducting PVA-PEG blended polymer electrolytes," Bulletin of Materials Science, vol. 34, no. 5, pp. 1063-1067, 2011.

[42] D. K. Pradhan, B. K. Samantaray, R. N. P. Choudhary, and A. K. Thakur, "Complex impedance studies on a layered perovskite ceramic oxide-NaNdTiO 4 ," Materials Science and Engineering: B, vol. 116, no. 1, pp. 7-13, 2005.

[43] L. Fan, Z. Dang, G. Wei, C. W. Nan, and M. Li, "Effect of nanosized $\mathrm{ZnO}$ on the electrical properties of $(\mathrm{PEO})_{16} \mathrm{LiClO}_{4}$ electrolytes," Materials Science and Engineering: B, vol. 99, no. $1-3$, pp. 340-343, 2003.

[44] P. A. R. D. Jayathilaka, M. A. K. L. Dissanayake, I. Albinsson, and B. E. Mellander, "Dielectric relaxation, ionic conductivity and thermal studies of the gel polymer electrolyte system PAN/EC/PC/LiTFSI," Solid State Ionics, vol. 156, no. 1-2, pp. 179-195, 2003.
[45] P. Khatri, B. Behera, V. Srinivas, and R. N. P. Choudhary, "Structural and dielectric properties of Ba3V2O8 ceramics," Current Applied Physics, vol. 9, no. 2, pp. 515-519, 2009.

[46] B. Louati, F. Hlel, and K. Guidara, "AC electrical properties and dielectric relaxation of the new mixed crystal $\left(\mathrm{Na}_{0.8} \mathrm{Ag}_{0.2}\right)_{2} \mathrm{PbP}_{2} \mathrm{O}_{7}$," Journal of Alloys and Compounds, vol. 486, no. 1-2, pp. 299-303, 2009.

[47] S. More, R. Dhokne, and S. Moharil, "Dielectric relaxation and electric modulus of polyvinyl alcohol-Zinc oxide composite films," Materials Research Express, vol. 4, no. 5, Article ID 055302, 2017.

[48] S. Dutta, R. N. P. Choudhary, and P. K. Sinha, "Impedance spectroscopy studies on $\mathrm{Fe}^{3+}$ ion modified PLZT ceramics," Ceramics International, vol. 33, no. 1, pp. 13-20, 2007.

[49] N. H. Idris, H. B. Senin, and A. K. Arof, "Dielectric spectra of LiTFSI-doped chitosan/PEO blends," Ionics, vol. 13, no. 4, pp. 213-217, 2007.

[50] A. S. Ayesh, "Dielectric relaxation and thermal stability of polycarbonate doped with $\mathrm{MnCl}_{2}$ salt," Journal of Thermoplastic Composite Materials, vol. 21, no. 4, pp. 309-322, 2008.

[51] S. B. Aziz, "The mixed contribution of ionic and electronic carriers to conductivity in chitosan based solid electrolytes mediated by CuNt salt," Journal of Inorganic and Organometallic Polymers and Materials, vol. 28, no. 5, pp. 1942-1952, 2018.

[52] S. B. Aziz, "Role of dielectric constant on ion transport: reformulated Arrhenius equation," Advances in Materials Science and Engineering, vol. 2016, Article ID 2527013, 11 pages, 2016.

[53] S. B. Aziz, Z. H. Z. Abidin, and A. K. Arof, "Influence of silver ion reduction on electrical modulus parameters of solid polymer electrolyte based on chitosan-silver triflate electrolyte membrane," Express Polymer Letters, vol. 4, no. 5, pp. 300310,2010

[54] D. K. Pradhan, R. N. P. Choudhary, and B. K. Samantaray, "Studies of structural, thermal and electrical behavior of polymer nanocomposite electrolytes," Express Polymer Letters, vol. 2, no. 9, pp. 630-638, 2008.

[55] Y. G. Marinov, G. B. Hadjichristov, A. G. Petrov, H. K. Koduru, L. Marino, and N. Scaramuzza, "Dielectric and electrical behaviours of polymeric (PEO/PVP): $\mathrm{NaIO}_{4}$ composite for solid electrolytes," Journal of Physics: Conference Series, vol. 794, Article ID 012020, 2017. 


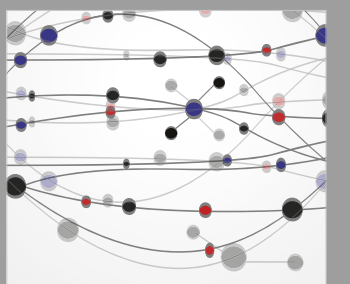

The Scientific World Journal
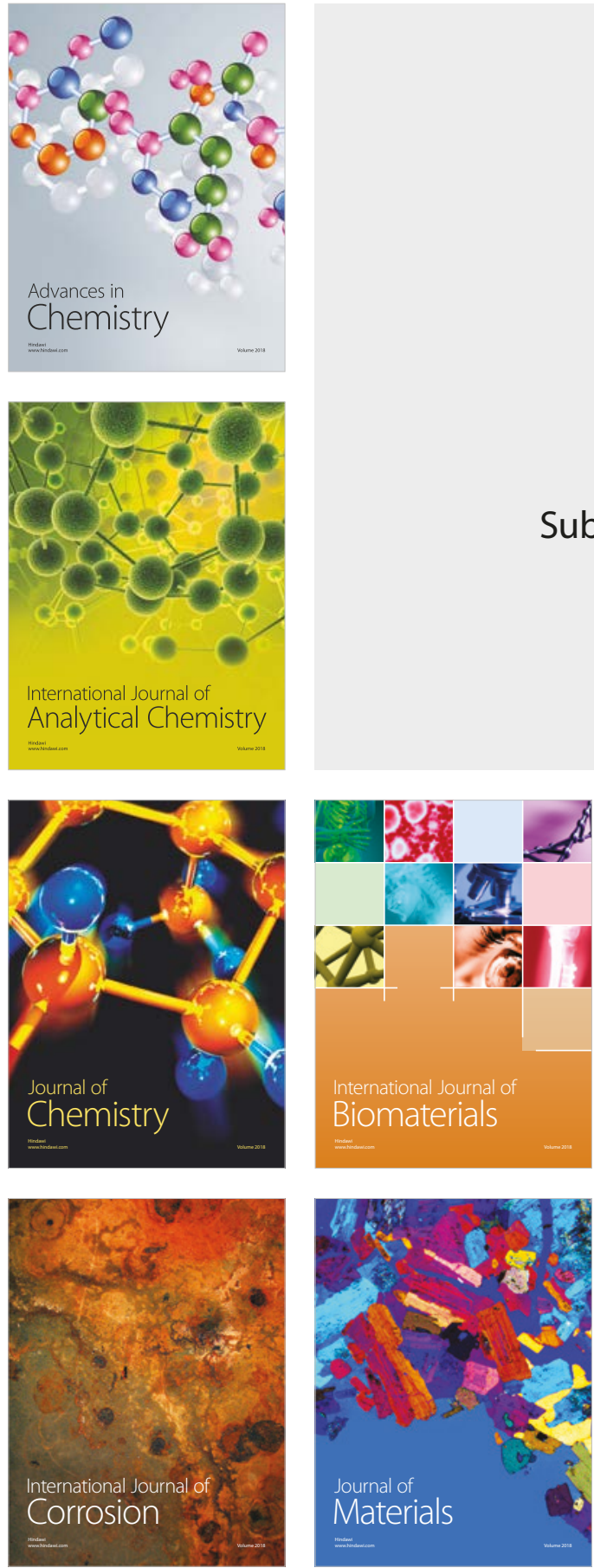

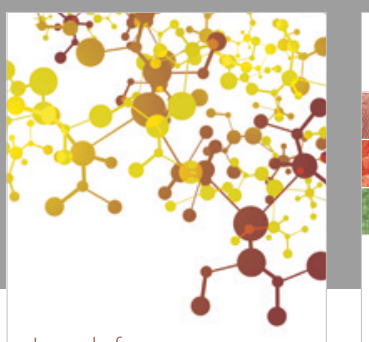

Journal of

Applied Chemistry
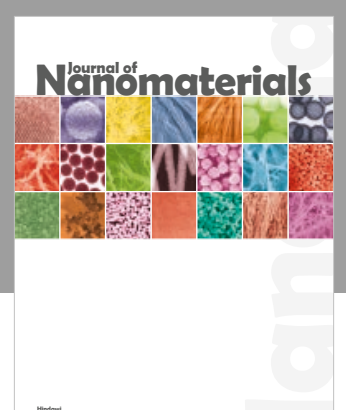

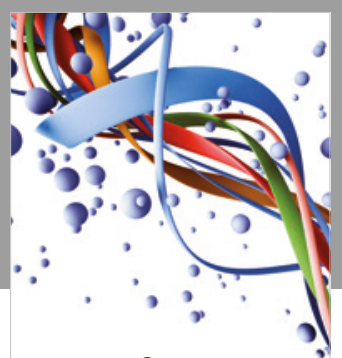

Scientifica

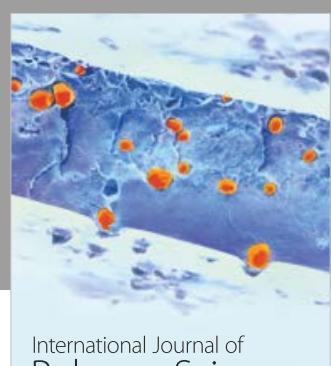

Polymer Science

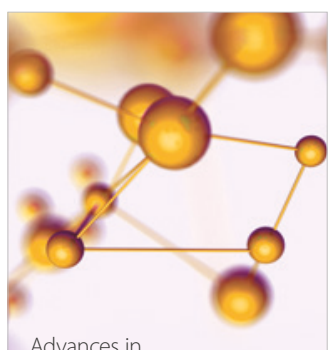

Physical Chemistry
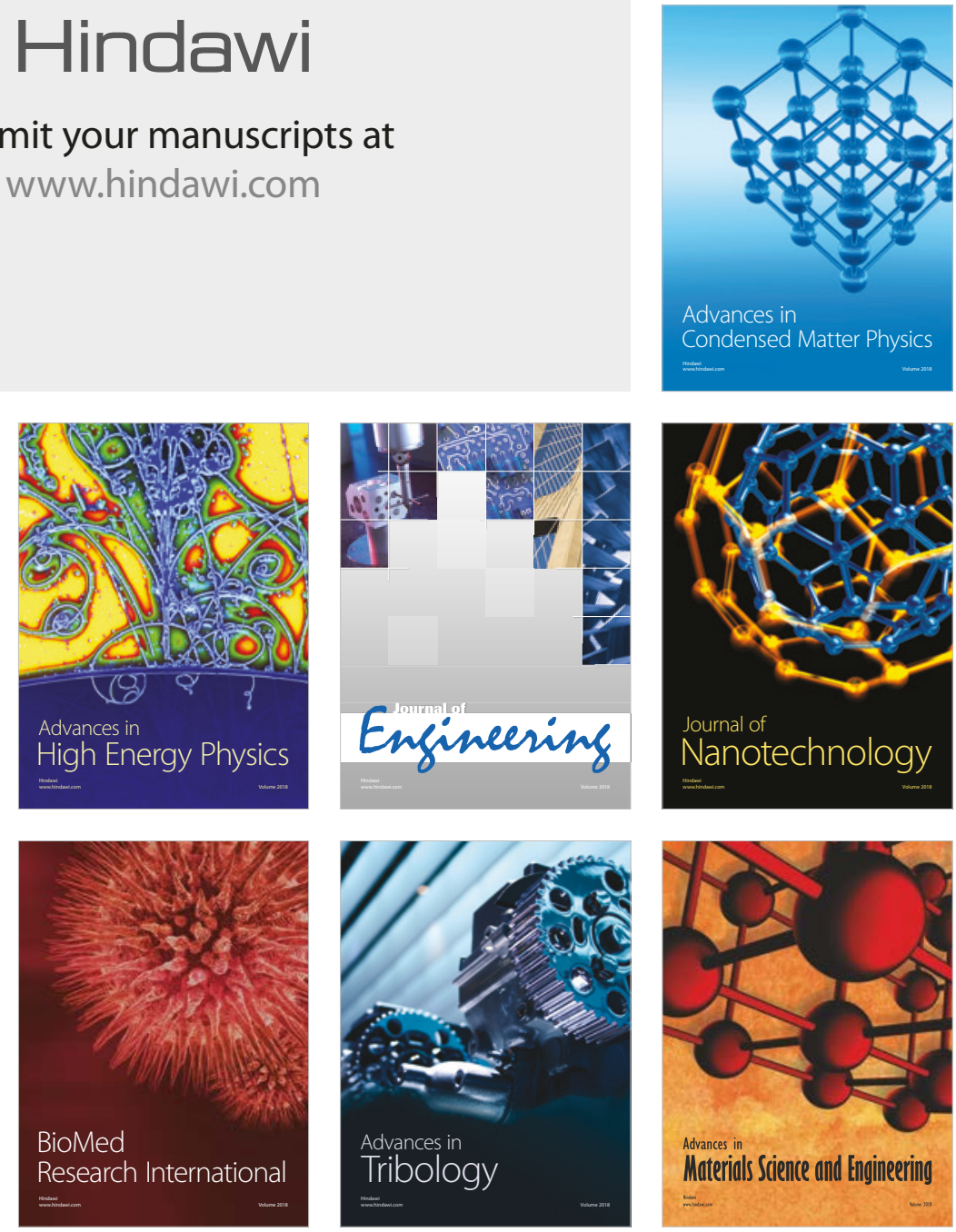